\title{
Análise de mitos africanos em uma comunidade quilombola: comunicação, informação e religiosidade
}

\author{
Analysis of African myths in a quilombola community: communication, \\ information and religiosity
}

\author{
Análisis de los mitos africanos en una comunidad quilombola: la \\ comunicación, la información y la religiosidad \\ Cleyciane Cássia Moreira Pereira \\ Maria Giovanna Guedes Farias ${ }^{2}$
}

\section{Resumo}

Esta comunicação apresenta resultados de pesquisa realizada na Comunidade Quilombola Alcantarense de Itamatatiua, localizada no Maranhão, cujo objetivo centrou-se em identificar e verificar como ocorre a preservação e a compreensão dos mitos africanos presentes nesta comunidade - a exemplo de Oxum, Iemanjá, Nana e Exu -, bem como a possibilidade de contribuição para a continuidade de estudos que retratem a história e memória negra. Esses mitos constituem-se como informações fundamentais das tradições dos moradores de Itamatatiua, os quais se preocupam em preservar os segredos, a religiosidade e as histórias vivenciadas por eles e pelos antepassados, repassando-as para os mais novos e para pesquisadores interessados pela oralidade. Para coleta e análise dos dados utilizou-se a mito análise, a partir da Teoria do Imaginário de Gilbert Durand, concomitante com a metodologia qualitativa de abordagem etnográfica. Os resultados demonstram que analisar as narrativas míticas em linhas diacrônicas e sincrônicas, contribui para o desvendamento de riquezas e tradições adormecidas em um passado de opressão e repressão, o qual pode ser reconstruído e devolvido às populações desconhecedoras de sua própria ancestralidade. Conclui-se que essas informações mitológicas, repassadas pela oralidade, podem, inclusive, devolver a autoestima dessa população.

Palavras-chave: Mitos africanos. Comunidade quilombola. Teoria do Imaginário.

\begin{abstract}

\begin{tabular}{|c|c|}
\hline \multirow{3}{*}{ 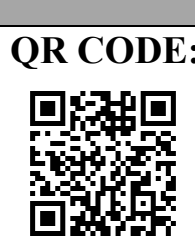 } & Acesse este artigo online \\
\hline & $\begin{array}{l}\text { Website: } \\
\text { http://www.revistas.ufg.br/index.php/ci }\end{array}$ \\
\hline & $\begin{array}{l}\text { DOI: } \\
\text { http://dx.doi.org/10.5216/ci.v19i2.3680 } \\
0\end{array}$ \\
\hline
\end{tabular}
\end{abstract}

This paper presents research results conducted in the Quilombola Community Alcantarense of Itamatatiua, located in Maranhão, whose goal focused on identify and verify how does the

preservation and understanding of African myths present in this community - like Oshun, Yemanja, Nana and Eshu - as well as the possibility of contributing to the continuity of studies that portray the history and black memory. These myths are as fundamental information of the traditions of the inhabitants of Itamatatiua, which are concerned to preserve the secrets, religion and stories experienced by them and by the ancestors, passing them to the newest and researchers interested by orality. To collect

\footnotetext{
${ }^{1}$ Doutoranda em Ciência da Informação da Universidade Federal da Bahia (PPGCI/UFBA). Mestre em Ciência da Informação pela Universidade Federal da Paraíba (PPGCI/UFPB). Brasil, Paraíba, João Pessoa. E-mail: cleycipereira@hotmail.com

${ }^{2}$ Doutora em Ciência da Informação da Universidade Federal da Bahia (PPGCI/UFBA). Mestre em Ciência da Informação pela Universidade Federal da Paraíba (PPGCI/UFPB). Graduada em Comunicação Social (Habilitação: Jornalismo) pela Universidade Estadual da Paraíba (UEPB). Professora do Departamento de Ciências da Informação da Universidade Federal do Ceara (UFC). Brasil, Fortaleza, Ceará. E-mail: mgiovannaguedes@gmail.com
}

Comun. \& Inf., Goiânia, GO, v. 19, n. 2, p. 53-70, jul./dez. 2016. 
and analyze the data we used the myth analysis, from the imaginary theory of Gilbert Durand, concomitant with qualitative methodology of ethnographic approach. The results show that analyze the mythical narratives in diachronic and synchronic lines, contributes to the unveiling of wealth and dormant traditions in a past of oppression and repression, which can be rebuilt and returned to populations unaware of his own ancestry. We conclude that these mythological information, passed on by oral tradition, may even return the self-esteem of this population.

Keywords: African Myths. Quilombola community. Imaginary theory.

\section{Resumen}

Este trabajo presenta los resultados de investigaciones realizadas en la Comunidad Quilombola Alcantarense de Itamatatiua, situada en Maranhão, cuyo objetivo se centro en identificar y verificar cómo hace la preservación y la comprensión de los mitos africanos presentes en esta comunidad - como Oshún, Yemanjá, Nana y Eshu -, así como la posibilidad de contribuir a la continuidad de los estudios que retratan la historia y la memoria negro. Estos mitos son información fundamental de las tradiciones de los habitantes de Itamatatiua, que se ocupan de preservar el secreto, la religión y las historias experimentado por ellos y por los antepasados, de pasarlos a los más nuevos y los investigadores interesados por la oralidad. Para recoger y analizar los datos se utilizó el análisis de mito, de la teoría imaginario de Gilbert Durand, concomitante con la metodología cualitativa de enfoque etnográfico. Los resultados muestran que el análisis de los relatos míticos en líneas diacrónicos y sincrónicos, contribuye a la inauguración de la riqueza y las tradiciones latentes en un pasado de opresión y represión, que puede ser reconstruido y regresó a las poblaciones ignorantes de su propia ascendencia. Llegamos a la conclusión de que esta información mitológica, transmitida por tradición oral, incluso puede devolver la autoestima de esta población.

Palabras clave: Mitos africanos. Comunidad Quilombola. Teoría imaginaria.

\section{INTRODUÇÃO}

$$
\begin{aligned}
& \text { voz guarda segredos que demarcam memórias, culturas e tradições. } \\
& \text { Quando os povos de matriz africana aportaram em solo brasileiro, } \\
& \text { trouxeram em suas narrativas orais, segredos que necessitam ser estudados }
\end{aligned}
$$
e compreendidos dentro de um quadro microssocial. Conforme Teixeira (1991, p. 91), este quadro "permite a apreensão da complexidade, heterogeneidade, e pluralidade que caracterizam o dado social de qualquer agrupamento humano. Em outras palavras, são pistas que podem mostrar o 'lado de sombra' da realidade", levando em conta as ações dos indivíduos que não estão regulamentadas em documentos formais, mas se sobrepõem imbuídas em grupos de afetividade, de funções simbólicas particulares.

Uma realidade oral reconhece a fala, segundo Vansina (2010, p. 139), “não apenas como um meio de comunicação diária, mas também como um meio de preservação da sabedoria dos ancestrais". Para preservar é necessário manter a tradição, um testemunho transmitido verbalmente de uma geração para outra. "Quase em toda parte, a palavra tem um poder misterioso, pois palavras criam coisas. Isso, pelo menos, é o que prevalece na maioria das civilizações africanas." Dessa forma, com o propósito de apontar alguns segredos sobre a

Comun. \& Inf., Goiânia, GO, v. 19, n. 2, p. 53-70, jul./dez. 2016. 
população de matriz africana, apresenta-se esta pesquisa realizada com os moradores da Comunidade Quilombola Alcantarense de Itamatatiua (CQAI) - localizada na cidade de Alcântara, estado do Maranhão -, a partir do fenômeno da oralidade, o qual é definido como "o processo de comunicação, o desenvolvimento da linguagem, a criação de uma parte muito importante da cultura e da esfera simbólica humana”. (LOZANO, 1996, p. 15).

Adota-se o tema mitos da cultura africana, por possibilitar invocar a memória, a história, as relíquias, as lembranças que, de acordo com Lowenthal (1985), constituem metáforas mútuas para o entendimento de rotas cruzadas em direção ao passado e entendimento de histórias como a dos Itamatatiuenses. Logo, essas vozes trazem informações que necessitam de cuidados para salvaguardar a memória de um povo com características identitárias. Como explica Bordenave (1982), um povo que adotou os modos de pensamento e de ação, crenças e valores, hábitos e tabus, utilizando para tal a comunicação como canal para aprender a ser membro de sua sociedade/comunidade.

Para tratar os dados coletados, utilizou-se a Teoria do Imaginário de Gilbert Durand a fim de desvendar as figuras mitológicas da Comunidade Quilombola, consideradas como heróis, Oxuns, Iemanjás, Nanãs e Exus que se mesclam no fazer, agir e pensar dos Itamatiuenses. Esses mitos constituem informações fundamentais das tradições dos moradores de Itamatatiua, os quais se preocupam em preservar a história e memória negra, repassando-as através da oralidade.

\section{COMUNIDADE QUILOMBOLA ALCANTARENSE DE ITAMATATIUA}

A Comunidade de Itamatatiua, de acordo com o Inventário Nacional de Bens Móveis e Integrados, surgiu no século XVIII e originou-se de uma fazenda da Ordem Carmelita ${ }^{3}$ dedicada à Santa Thereza. Segundo dona Neide de Jesus, líder e representante da Comunidade, o surgimento data de 1699 e o aniversário de Itamatatiua é comemorado em 03 de junho.

As 132 famílias $^{4}$ que compõem a CQAI têm como principais fontes de renda a agricultura de subsistência, a cerâmica e a aposentadoria. Além do recebimento de benefícios de programas do Governo Federal, como Bolsa Escola, Bolsa Família e outros. A Comunidade é permeada por caracteres que a tornam singular, por exemplo, a denominação de quilombola

\footnotetext{
${ }^{3}$ Em 1797, o Reverendo Prior João Alves Serrão descreveu os "bens" referentes à Ordem do Carmo em Alcântara, ressaltando que "[...] a fazenda dedicada à Santa Thereza conta com 135 escravos entre homens e mulheres, capazes de serviço 63, doentes e velhos 23, e menores 49 [...].” (BRASIL, 1999, p. 2).

${ }^{4}$ Quantidade fornecida em 2010 pela Agente de Saúde da Comunidade.
}

Comun. \& Inf., Goiânia, GO, v. 19, n. 2, p. 53-70, jul./dez. 2016. 
numa abordagem tradicional é concebida como o local escondido, geralmente no mato onde abrigavam os negros fugitivos dos cativeiros. (AQUINO; PEREIRA, 2010).

Em Itamatatiua, a formação do grupo de quilombolas se dá em decorrência da saída da Ordem Carmelita da propriedade. Por não haver compradores para a terra, a fazenda foi consentida para os negros que ali residiam. Até hoje, a Comunidade é conhecida como sendo a Terra de Santa D’Ávila de Jesus. Em 1878, a posse da Terra foi repassada aos negros Itamatatiuenses pela Ordem religiosa com uma inscrição em uma pedra em latim "Colonist St. There mandada edificar Ex ${ }^{\circ}$ Prc. Cd. Graciliano A. P. Pimentel 25 d'agosto de 1878 derl M.J.C.”, a qual foi atestada como documento de posse, e seu valor simbólico/legal foi reconhecido em audiência pública, decorrente de algumas disputas pela terra ${ }^{5}$. Cabe mencionar a devoção que esses quilombolas têm a Santa, adotando em seus sobrenomes, com raras exceções, o sobrenome "de Jesus", e, por este motivo, são conhecidos como os Pretos de Santa Tereza de Jesus.

Nas últimas décadas, os quilombolas itamatatiuenses têm conseguido melhorias para a Comunidade, sobretudo, advindas das reivindicações da Associação de Mulheres Ceramistas $^{6}$, a exemplo da instalação de um poço artesiano que abastece algumas residências, energia elétrica, um caminhão para auxiliar na fabricação e transporte da cerâmica. Por outro lado, assim como as demais comunidades rurais, as comunidades quilombolas são desprovidas de saneamento básico, água tratada e posto de saúde. Em Itamatatiua quando os moradores adoecem, precisam se deslocar para hospital de municípios vizinhos. Entretanto, antes de procurarem um médico, eles utilizam o saber popular transmitido pela oralidade para se tratarem com as ervas locais.

A forma de comunicação na Comunidade Quilombola de Itamatatiua, mesmo em meio à chegada do rádio, da televisão e da internet, ainda prevalece a oralidade. Esta é permeada de lendas, narrativas em que aparecem curupiras, mãe d'águas, figuras do imaginário popular. Santos; Rei; Oosterbeek (2010) contam que ao adentrar na comunidade de Itamatatiua, é possível perceber a presença da oralidade e das tradições vinculadas a ela, seja nas suas práticas sociais, como em seu aspecto físico-geográfico. Dessa forma, esta pesquisa é conduzida a

\footnotetext{
${ }^{5}$ Um dos entrevistados relatou um episódio em que foi convocado para uma audiência sobre a posse da Terra com fazendeiros que queriam tomá-las dos quilombolas, ao mostrarem a Pedra ao juiz no fórum, este disse que a sessão estava encerrada, pois a Pedra era uma prova legítima. Apesar de os moradores não possuírem a titulação das terras, eles têm o reconhecimento da propriedade e suas casas realizado em 2006 pela Fundação Palmares.

${ }^{6}$ Associação de Mulheres foi organizada há cerca de 10 anos conforme dona Neide. Elas se organizam na fabricação e vendas da cerâmica, e possuem uma representante que é escolhida através de eleição direta a cada dois anos. É através dessa organização que as mulheres da Comunidade conquistam benefícios para si e para os demais moradores.
}

Comun. \& Inf., Goiânia, GO, v. 19, n. 2, p. 53-70, jul./dez. 2016 
identificar, por meio da oralidade, os mitos africanos que se apresentam nas práticas culturais, na história e, sobretudo nas narrativas dos quilombolas itamatatiuenses.

\section{ITINERÁRIO METODOLÓGICO}

A teoria durandiana mostra que, na medida em que, a razão perde seu espaço de senhora absoluta da verdade e dos problemas que assolam a sociedade, insere-se no universo acadêmico e social o estudo do símbolo e do imaginário. Esta teoria permite revelar a importância do mundo subjetivo, interpretativo, imaginário inerente ao homem com o propósito de reconhecer as imagens que estruturam suas obras e a si mesmo, como soluções para o desvendamento de aspectos nunca abordados no estudo humano.

Para encontrar as imagens significativas da representação humana, Durand (1997) recorre à "Antropologia profunda", ou seja, utiliza-se de várias ciências, com seus diferentes métodos e disciplinas com o objetivo de explicar um aspecto de uma ciência por meio de outras ciências. Essa Antropologia consiste da interação biopsiquicosocial, isto é, um percurso de formação das imagens do corpo, mente e cultura, e considera os símbolos, esquemas e arquétipos elementos constitutivos dessa trajetória, por serem homólogos e isomorfos, dotados de características básicas e similares, classificados em constelações de imagens e, por conseguinte, resultam em grandes constelações - as estruturas do imaginário.

Além da teoria de Durand, utilizou-se, para tratar os dados coletados nesta pesquisa, a abordagem qualitativa e as características etnográficas, definidas por Geertz $(1989$, p. 15), como um "esforço intelectual para uma descrição densa". Entretanto, adotou-se essa modalidade de análise não nessa acepção de leitura em profundidade do espaço proposta por Geertz, mas fez-se uso de alguns de seus pressupostos e instrumentos metodológicos.

Já os instrumentos de pesquisa usados para coletar os dados foram: entrevistas semiestruturadas, observação direta e ficha de informante. A partir destes instrumentos, realizou-se 24 entrevistas no período de 17 a 29 de janeiro e 02 a 13 de fevereiro de 2010 . Entrevistou-se os seguintes sujeitos: a) a senhora mais idosa, que é remanescente do período escravista com 105 anos; b) as mulheres líderes, visto que, no campo de pesquisa, prevalece uma cultura de tradição matriarcal, em que elas comandam e representam a localidade; c) os responsáveis (pais ou mães) pela família que aceitassem ser entrevistados; d) e conversas com jovens sem considerá-los como focos prioritários da coleta, mas colaboradores, a fim de visualizar como se desencadeava a perpetuação da memória oral e propagação das tradições locais.

Comun. \& Inf., Goiânia, GO, v. 19, n. 2, p. 53-70, jul./dez. 2016. 
Todas as entrevistas foram ouvidas, mas selecionou-se 10 para serem transcritas na íntegra. O critério de escolha foi baseado no objetivo de apresentar um retrato do conhecimento e das narrativas que alguns moradores detêm sobre a Comunidade de Itamamtatiua. Vale destacar que cada entrevistado recebeu nomes fictícios (Xangô, Laroyê, Odoyá, Oyê, Oya, Ogunhê, Epa, Eparrê, Okê e Olariê). Nas falas dos entrevistados, identificou-se os mitos africanos baseados nos orixás dos povos iorubás e orientados pela tabela disposta na obra de Prandi (1996). Após a identificação dos mitos, foram extraídos os fragmentos de relatos de entrevistados, onde foram localizadas essas narrativas míticas Em seguida, as entrevistas transcritas passaram por uma releitura, visando aprofundar a caracterização dos mitos inerentes ao contexto Itamatatiuense e buscar o confronto com as imagens fornecidas pela teoria durandiana e suas significações.

Para prosseguir com a mitoanálise, a pesquisa foi baseada em três aspectos da cultura Itamatatiuense: educação, lazer e saúde. Identificaram-se os mitos africanos que se manifestaram em cada um desses aspectos a partir da metodologia proposta por Durand (1997), a qual é composta pela Bacia semântica e Tópica diagramática, componentes esses que orientaram na localização dos mitos latentes e patentes inerentes aos elementos iconográficos e as narrativas dos moradores Itamatatiuenses. É relevante mencionar, que nesta comunicação apresentam-se apenas os mitos africanos de Oxum, Iemanjá, Nana e Exu, e a mitoanálise no contexto educacional.

\section{MITOS DA CULTURA AFRICANA NA COMUNIDADE DE ITAMATATIUA}

$\mathrm{Na}$ localidade dos iorubás, o relato de um mito africano demonstra que Exu (mensageiro da comunicação entre o adivinho e Orunmilá) foi incumbido da missão de encontrar soluções, para problemas terríveis que atormentavam os homens. Para cumprir tal intento, Exu deveria ouvir todas as histórias das divindades, dos animais, dos seres humanos, além daqueles que dividissem com ele a Terra, e ficassem atentos sobre quais providências seriam tomadas, bem como as oferendas que deveriam ser feitas aos deuses para que todos os desafios fossem vencidos, (AQUINO; PEREIRA, 2010). Ainda conforme as autoras, Exu conseguiu colecionar 301 histórias, e por isso, ele tinha diante de si, o conhecimento para desvendar os mistérios sobre a origem e governo do mundo dos homens e da natureza, inclusive daqueles infortúnios do cotidiano, como as doenças e a morte. Todas essas histórias foram entregues a Orunmilá (Deus do oráculo) para que transmitisse esse conhecimento aos seus

Comun. \& Inf., Goiânia, GO, v. 19, n. 2, p. 53-70, jul./dez. 2016. 
seguidores - os babalaôs ou pais do segredo - pois, como explica Prandi (2000), para os iorubás antigos, nada é novidade, tudo que acontece já teria ocorrido.

Logo, compreendendo pela linha iorubana que todo acontecimento pode se reportar a algo que já teria acontecido, esta pesquisa teve como missão identificar o panteão mítico em solo Itamatatiuense, auxiliado pelo Regime Diurno e Noturno das Estruturas Antropológicas de Gilbert Durand. Utilizou-se esse Regime como bússola, na busca da identificação dos mitos patentes e latentes que permeiam a Comunidade Quilombola, e outras figuras mitológicas africanas, que se diluem e enfraquecem em meio aos discursos de racionalização nas práticas sociais, religiosas, políticas e ideologias dessa tradição.

\subsection{HISTÓRIAS SOBRE A SANTA TEREZA D’ÁVILA DE JESUS}

Dentre as narrativas que suscitaram os desvendamentos de mistérios simbólicos, encontrou-se as personagens e as figuras mitológicas de Santa Teresa D’Ávila de Jesus. A santa nasceu em Ávila, Espanha, no século XVI (1515), e ingressou no Carmelo de Ávila aos vinte anos, convertendo-se pouco tempo depois, tornando-se um espírito modelo de devoção a Igreja. Faleceu aos 67 anos na cidade de Alba de Tormes e foi canonizada em 1662. O Papa Paulo VI reconheceu o título de Doutora da Igreja em 27 de setembro de 1970. (CANÇÃO NOVA, 2010).

A Ordem do Carmo chegou ao Brasil no século XVI, instalando-se em Olinda, Pernambuco, em 1580 no século XV, onde também construíram em 1586 o primeiro Convento do Carmo. Despontou na Província do Grão Pará e no Maranhão no século XVIII já com a ramificação dos Carmelitas Reformados ou Descalços, por sua vez, esta foi uma Reforma que a Santa Teresa esteve à frente para sua efetivação. (MOLINA, 2006)

$\mathrm{Na}$ Comunidade de Itamatatiua, Santa Tereza é considerada protetora e dona da terra. Segundo os moradores, mesmo sendo uma das comunidades mais carentes ${ }^{7}$ da região, ninguém passa fome, e todos sempre obtêm curas para as doenças. Um milagre recebido por Ogunhê ${ }^{8}$, Eparrê e Olariê é descrito no fragmento da narrativa:

Ogunhê: Meu irmão saiu pra trabalhar. Ano passado minha mãe saiu em Janeiro para São Luís para operar dos olhos e passou seis meses, aí quando foi em Julho a mãe dela disse: Minha Santa Tereza se vós fizer que meu filho volte (ela começou a chorar ... pausa), eu mando rezar uma ladainha com bolo. Minha irmã! Não deu prazo de um mês. Quando foi um dia meu sobrinho chegou e disse: Tia tem um moço aí na porta, aí eu disse: moço, que moço,

\footnotetext{
${ }^{7}$ Ela não é uma das Comunidades mais carentes da região, mas essa afirmação foi dada por alguns moradores Itamatatiuenses quando falavam da ação, da providência da Santa Tereza D’Ávila de Jesus na vida da Comunidade. ${ }^{8}$ Ogunhê relatando um milagre recebido da Santa sobre a chegada de um filho que saiu para trabalhar e nunca mais voltou, e a mãe fez uma promessa.
}

Comun. \& Inf., Goiânia, GO, v. 19, n. 2, p. 53-70, jul./dez. 2016. 
não é ninguém lá de casa não, não tia. Aí eu fiquei curiosa. Aí ele disse: é de casa. Aí eu vim, mamãe é Antoninho!!! Mamãe disse: é Antoninho?! Quando foi no outro final de semana ela mandou rezar um ladainha com café, bolo, foi linda ela, muita gente, muita gente!!

Eparrê: Ela pra mim é muito milagrosa, quando eu assim tô aperriado, eu vou lá, faço minha conversinha com ela, é pode botar fé, ela é milagrosa mesmo, pode botar fé mesmo.

Pesquisadora: O que falam sobre a Santa?

Olariê: Há! Essa Santa é, é uma Santa que agente tem o respeito por Ela, aqui na Comunidade, e mesmo os devotos de Pinheiro, Bequimão, de Alcântara, também tem muito respeito por ela. É! (Informação verbal). ${ }^{9}$

Nessas narrativas, é possível localizar o sagrado, desencadeado na imagem da Santa Tereza D'Ávila e na vida dos Itamatatiuenses, e encontrar os semblantes femininos, tais como Oxum, Iemanjá. No interior das estruturas do imaginário, o feminino, pelos símbolos que relaciona, tem sido associado à vida pelo mistério da maternidade que lhe é próprio.

\subsection{A FONTE DO CHORA: UM LUGAR ENCANTADO}

Dentre as versões contadas para explicar a chegada da Santa à Comunidade, existe uma que foi encontrada na Fonte do Chora $^{10}$ (ver figura 1). Esse acontecimento com muita frequência é relacionado ao motivo do surgimento dessa Comunidade. A narrativa de Odoyá apresenta dados sobre a origem da Comunidade:

Pesquisadora: O que a Senhora sabe sobre a origem da Comunidade, de onde vem Itamatatiua?

Odoyá: Eu não sei nem contar muito. Mas segundo o que alguém mais antigo me contou, porque eu também sou curiosa. Itamatatiua...assim era um povoado menor, só tinha as casas, o que quê aconteceu? As pessoas me disseram que Santa Teresa, uns dizem que ela apareceu aqui, andava, botava o rastinho na areia, eles botavam ela pra Igreja e no outro dia ela já amanhecia lá no Chora, eu não tenho nem assim como afirmar, né? As pessoas falavam que Santa Teresa foi encontrada no (Fonte do) Chora. Mas segundo me disseram ela veio de Roma, no tempo das Carmelitas. Aqui era uma fazenda antiga. Essa fazenda era ainda de um pessoal que...que acho que trouxeram alguém, os escravos. O certo era que as Carmelitas que eram donas dessas terras, 55 mil hectares. (informação verbal) ${ }^{11}$.

\footnotetext{
${ }^{9}$ Entrevista concedida por Ogunhê, Eparrê e Olariê em outubro de 2010, em Itamatatiua.

${ }^{10}$ Uma fonte utilizada pelos moradores. É um local encantado, onde os habitantes locais devem respeitar certos horários para não verem personagens como: sapos de ouro; peixes que sujam a água; mulheres que impedem a retirada d'água; curupira, dentre outros. Os visitantes devem pedir licença aos encantados da Fonte para utilizá-la. De acordo com moradores, a fonte teria surgido antes do início da Comunidade.

${ }^{11}$ Informação cedida por dona Odoyá, em Itamatatiua, 2010.
}

Comun. \& Inf., Goiânia, GO, v. 19, n. 2, p. 53-70, jul./dez. 2016. 


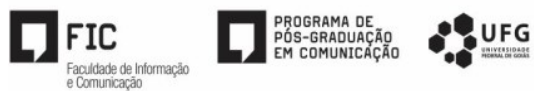

Comunicação

Informaçāo

Figura 1 - Fonte do Chora

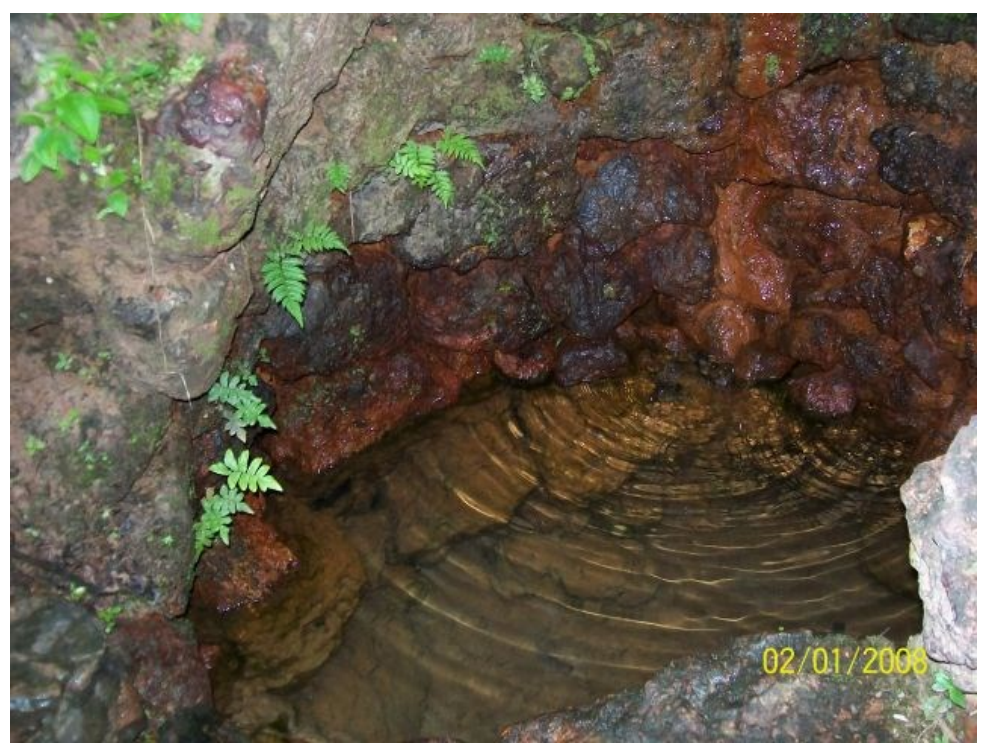

Fonte: Dados da pesquisa, 2011

Na mitologia africana existe o mito de Oxum (ver figura 2), divindade feminina da nação Ijexá (Nigéria), representante das águas doces dos rios e das cachoeiras, da riqueza, do amor, da prosperidade e da beleza, do ouro; cultuada em todas as religiões afro-brasileiras. $\mathrm{Na}$ natureza, o seu culto é realizado próximo de rios, cachoeiras e fontes de águas mineiras (OXUM, 2010).

Figura 2 - Oxum

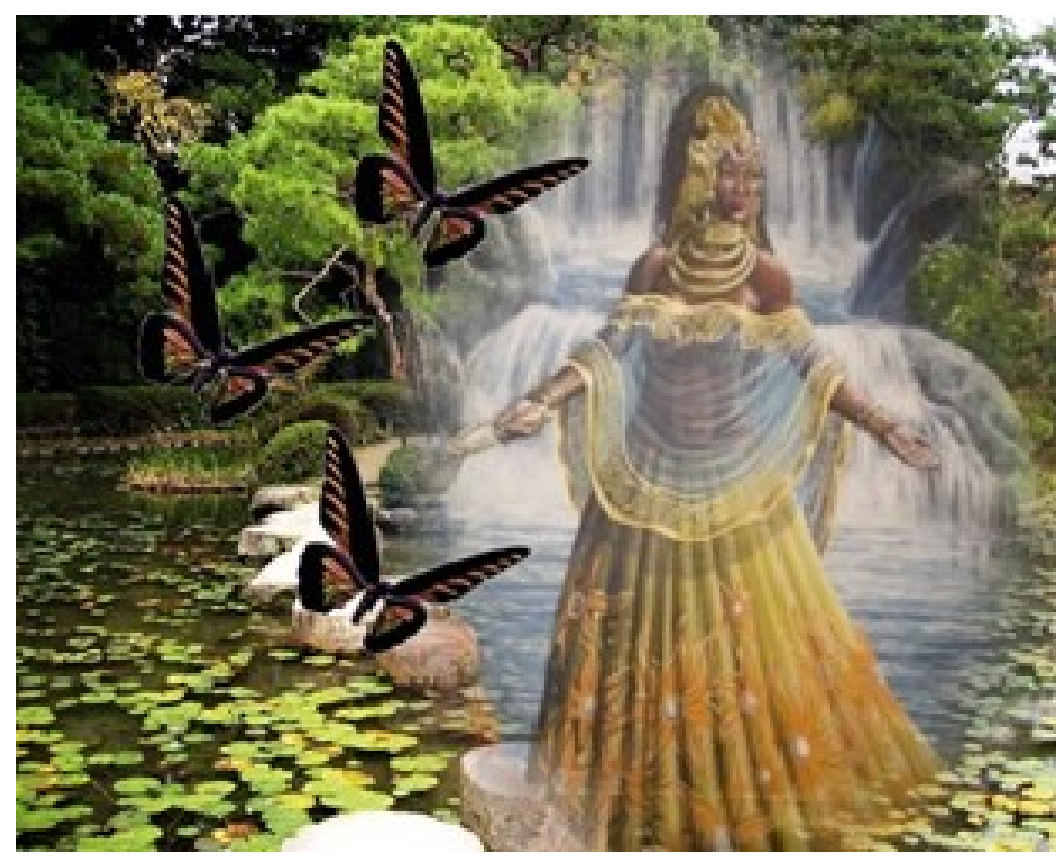

Fonte: www.comunidade-espiritual.com

Comun. \& Inf., Goiânia, GO, v. 19, n. 2, p. 53-70, jul./dez. 2016. 
Oxum, vestida com seu dourado, é o centro, onde as águas que a cercam representam como ela, a fecundidade. Segundo Eliade (2008) desde a pré-história, o conjunto Água-Mulher tem sido percebido como o circuito antropocósmico da fecundidade. Mas para algumas sociedades, as águas também representam o sêmen que fecunda a terra. Essas águas são purificadoras; água que os Itamatatiuenses precisam beber para renovar-se; os peixes, os sapos e outros encantados que aparecem impedindo as pessoas de visitarem a fonte ou mesmo de utilizarem suas águas em determinados horários.

Neste contexto, pode se visualizar análogos como: "aos monstros que sempre as vias da salvação, isto é, montam guarda à volta da árvore da vida ou de outro dos seus símbolos." (ELIADE, 2008, p. 235). Neste caso, “os monstros" cuidam, montam guarda para preservação das águas do Chora, podendo ser consideradas como fonte de vida. Na Teoria durandiana, a água "é utilizada mais especialmente como elemento de adorno pelos heroicos e, em particular, nos sujeitos femininos.” (DURAND, 1998, p. 186). A água que serve de adorno para Oxum é a mesma que dá vida a Comunidade, cessando a sede dos seus filhos Itamatatiuenses, fecundando suas terras e refazendo a história e vida desses moradores. Alguns fragmentos de narrativas nos levam a refletir sobre a Fonte do Chora com as palavras de Oyê, Oya, Olariê e Odoyá:

Oyê: Eu sei dizer que parece que encontraram a Santa lá no Chora, eu só sei dizer que a água de lá é uma beleza e não é todo mundo que vai lá. Tem gente que vai lá que a água fica pretinha que é um barro quando eles não gostam da gente, a água fica suja, já cansô de ter a época da Festa quando agente vai pra lá encher água, a dona de lá suja a água todinha e não enchiam (informação verbal). ${ }^{12}$

Oya: Eu já me entendi com o Chora, e nós bebia lá a água do Chora e eu me perguntava quem fez o Chora, olhe me diziam o Chora agente já encontrou, agora agente foi zelar por ele e fomo alimpar e perguntei por que botaram o nome Chora é porque todo tempo ele fica chorando aquela água da parede mesmo, eliminando aquela água pingando assim, aí butaram o nome Chora e morre com esse nome... e o pessoal de Tamatatiua tem essa água aqui encanada, mas eles não largaram de ir buscar a água do Chora para beber, está sempre limpa, sempre limpa (informação verbal). ${ }^{13}$

Compreende-se que, o culto a Santa Teresa teria sido decorrente do sincretismo religioso, proveniente dos negros que ao chegarem ao Brasil mantiveram suas tradições. Logo, os quilombolas ao permanecerem na Fazenda dos Carmelitas em Alcântara, continuaram com seus cultos religiosos à deusa africana Oxum. A Igreja Católica reprimia essas práticas

\footnotetext{
${ }^{12}$ Entrevista concedida por Oyê, em setembro de 2010.

${ }^{13}$ Entrevista concedida por Oya, em setembro de 2010.
}

Comun. \& Inf., Goiânia, GO, v. 19, n. 2, p. 53-70, jul./dez. 2016. 
religiosas africanas, o que na África ocorria em locais abertos. Conforme as palavras de Abdias Nascimento - em entrevista concedida a Juarez Tadeu de Paula Xavier - a religiosidade afrobrasileira era considerada anormalidade mental dos negros:

Os cultos afro-brasileiros eram uma questão de polícia. Dava cadeia. Até hoje, nos museus da polícia do Rio de Janeiro ou da Bahia, podemos encontrar artefatos cultuais retidos. São peças que provavam a suposta deliquência ou anormalidade mental da comunidade negra. Na Bahia, o Instituto Nina Rodrigues mostra exatamente isso: que o negro era um camarada doente da cabeça por ter sua própria crença, seus próprios valores, sua liturgia e seu culto. Eles não podiam aceitar isso. (NASCIMENTO, 2010) ${ }^{14}$.

Assim, os negros adotaram aos poucos os santos católicos para reverenciarem seus orixás, ou seja, esses santos eram "intermediários" para os quilombolas chegarem, por meio da fé, até seus orixás. Outra hipótese suscitada é a de que os religiosos da Ordem do Carmo, ao observarem as manifestações religiosas próximas a Fonte do Chora, inserem imagens de santos. As histórias em torno da religiosidade foram se reconfigurando ao longo dos séculos intrínsecas ao existir dos negros de Itamatatiua, com o propósito de substituírem suas crenças africanas pela católica, mesmo havendo resistência por parte destes. Configurando o que Valente (1994, p. 82) expõe: "é lícito supor que, entre as diversas formas sincréticas assumidas, os escravos negros podiam utilizar os santos católicos como "máscaras" para seus orixás, fazendo a correspondência entre as entidades negras e aquelas do hagiológico católico".

Infere-se que a Comunidade por ter uma gênese indígena, e os negros por não possuírem o mar próximo à sua localidade, cultuam a deusa Iemanjá em águas doces no Poço do Chora, visto a recorrência com que a Mãe D’água se mostra na oralidade desses moradores, o que pode ser observado no fragmento da entrevista com Olariê:

Pesquisadora: Quais as lendas, histórias que a senhora conhece sobre o Poço do Chora?

Olariê: Ah, o Poço do Chora? Ele lá tem Mãe d’Água

Pesquisadora: A senhora já viu?

Olariê: Eu ainda não vi, mas um tio meu cansou de vê. Ele via, lá esse tempo era muito mato, num sabe? Lá era fechado o mato, ai ele veio pra cá quando ele voltou, quando ele voltou era $12 \mathrm{~h}$, aí ele viu uma Mãe d'Água sentada naquela pedra, aquela pedra que tem, naum tem uma pedra bem assim? Ai ela tava sentada lá, aí quando ele fez ê, ela thum dentro do poço [...] Até pouco tempo Mãe d'Água assuviava muito, outro dia ela passou assuviando, fiiiti

Pesquisadora: Foi?

Olariê: Hum hum

Pesquisadora: Vocês sabem logo quando é ela?

Olariê: Hum hum. Sabe. Ai ela faz fiiiti, eu fiiiiti mas grosso, ô as Mãe d'Águas tão pôr ai (Informação verbal). ${ }^{15}$

14 Entrevista concedida a Juarez Tadeu de Paula Xavier por Abdias Nascimento. Disponível em:<http://pt.wikipedia.org/wiki/Candombl\%C3\%A9\#cite_note-11>. Acesso em: 10 ago. 2010.

${ }^{15}$ Entrevista concedida por Olariê em setembro de 2010, em Itamatatiua.

Comun. \& Inf., Goiânia, GO, v. 19, n. 2, p. 53-70, jul./dez. 2016. 
Ao emergir na tradição Itamatatiuense é possível identificar também o mito de Iemanjá (ver figura 3), Nigéria, a deusa das águas sincretizada no Brasil como Nossa Senhora da Conceição. Silva (2005) relata em um de seus mitos que ela era uma divindade responsável pelas águas doces do rio. Entretanto, fugindo do seu esposo, desemboca no mar, onde vive junto com sua mãe Okun.

Figura 3 - Iemanjá

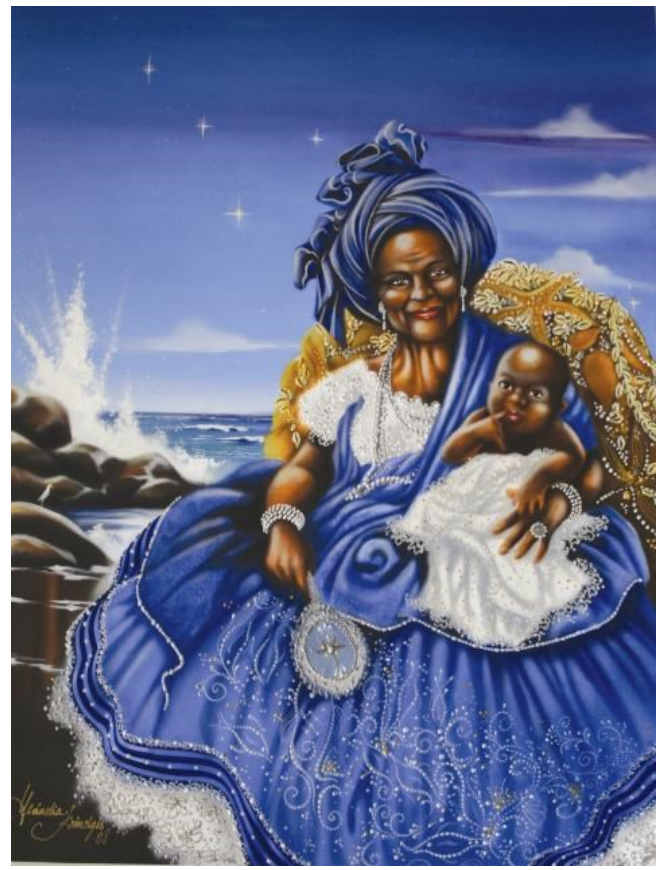

Fonte: http://portoalegre.olx.com.br/ile-nana-tolabi-geraldo-de-iemanja-iid-16981602

Em solo brasileiro é cultuada, sobretudo no mar, mas é comumente associada a encantados das águas doces de origem indígena, como Mãe D’água, Sereia, Iara, etc. Os filhos desse orixá são pessoas muito trabalhadoras e gostam de se livrar da pobreza; pode-se perceber traços dessa divindade nas mulheres Itamatiuenses frente às lutas da organização da Associação de cerâmica e da força com que lideram sua Comunidade. Cabe evidenciar que o primeiro candidato a um cargo político proveniente da Comunidade foi uma jovem, Marinete de Jesus ${ }^{16}$, que em 2008 estava obstinada a lutar por melhorias para sua localidade, que sofria com descaso e esquecimento por parte do governo local.

\footnotetext{
${ }^{16}$ Marinete de Jesus não foi eleita. Ela informou que mesmo assim não desistiu da carreira política.
}

Comun. \& Inf., Goiânia, GO, v. 19, n. 2, p. 53-70, jul./dez. 2016. 


\subsection{O ARTESANATO COMO PRESERVAÇÃO DAS TRADIÇÕES}

Na Comunidade de Itamatatiua, a forma de fabricação de peças de cerâmica é repassada de geração em geração, podendo até ser anterior à chegada dos negros. Possivelmente, foi iniciada pelos indígenas, que repassaram os ensinamentos aos moradores itamatatiuenses sobre a confecção da cerâmica e das telhas a partir do barro. Os fragmentos da narrativa de Okê mostram um dessa arte:

Esse trabalho de cerâmica é muito antigo, tem mais de duzentos anos, não era só pote, essas coisas, também tinha olaria, fazia tijolos, telhas. Eu acho que é antes dos Carmelitas porque dizem que aqui já moraram índios e cerâmica faz parte muito de negócio de índio, eu acho que já existia, aqui agente cava buraco e encontra muito pedaço, caco de telha, quando agente cava ali pro cemitério é ôh agente encontra só isso, pena que os mais novos não querem se engajar (Informação verbal) ${ }^{17}$.

Para ajudar na produção das peças de cerâmica, os moradores recorrem a outro mito, que se mostra inerente à tradição da Comunidade de Itamatatiua, a orixá Nanã (ver figura 4), deusa da lama, dos pântanos, do lodo; é a terra em contato com a água; a chuva, a tempestade.

Figura 4 - Nanã

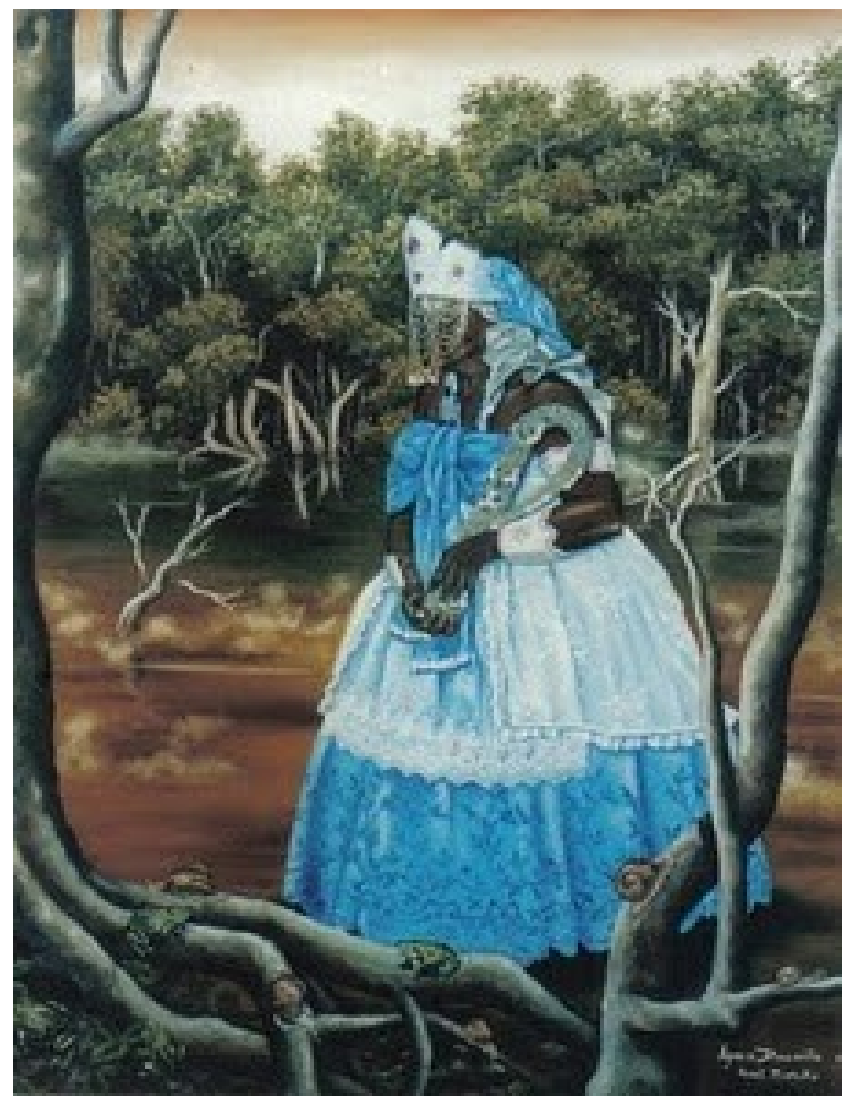

Fonte: http://povo-umbanda.blogspot.com/2010/07/oracao-nana.html

\footnotetext{
${ }^{17}$ Entrevista concedida por Okê em outubro de 2010, em Itamatatiua.
}

Comun. \& Inf., Goiânia, GO, v. 19, n. 2, p. 53-70, jul./dez. 2016. 
Ela é conhecida como uma das mais temidas e respeitadas orixás, pois representa a própria morte. Em seus cânticos são feitas súplicas para que leve a Ilku (morte) para longe e conceda que a vida seja mantida. Essa deusa nos remete a fecundação do sêmen, água na terra brotando, ingredientes que auxiliam na preservação de tradições que se propagam por séculos.

\subsection{REPRESENTAÇÃO DE IGBA EXU EM PEÇA DE CERÂMICA}

A peça de cerâmica, localizada na entrada da Associação e confeccionada pelas ceramistas itamatatiuenses, foi produzida numa oficina na própria localidade que se assemelha ao assentamento de Exu (ver figura 5).

Figura 5 - Cerâmica de Itamatatiua

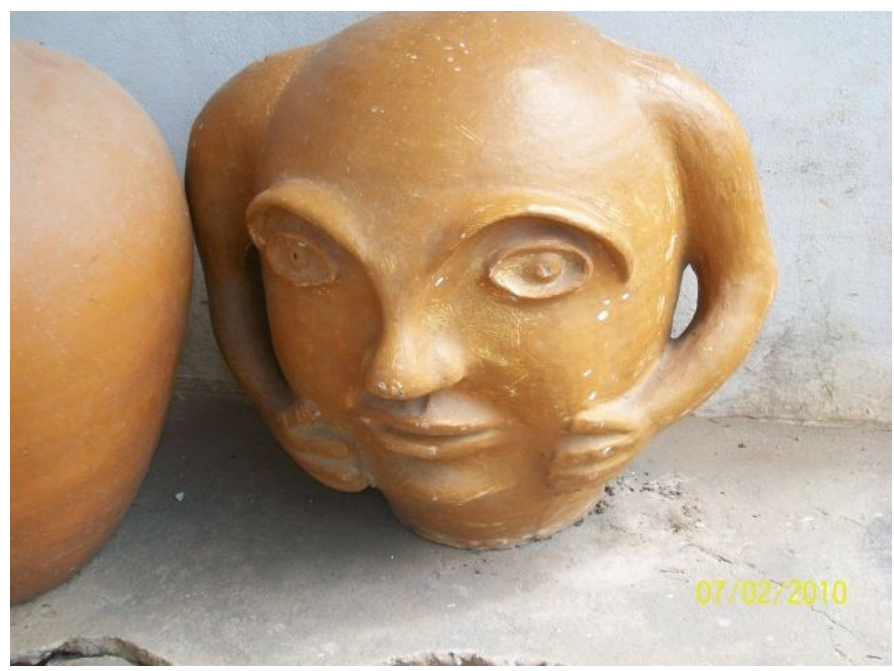

Fonte: Dados da pesquisa, 2011.

Já a figura abaixo (ver figura 6) representa Igba Exu ou assentamento de Exu, é confeccionado de formas diversas, a partir do barro ou do ferro, modelado com tabatinga, em forma humana completa ou apenas o busto, com olhos e boca feitos de búzios. (HARTMANN, 1980). Assim, a peça produzida na Comunidade chama a atenção pela semelhança, pois as moradoras que a produziram, não sabiam da existência de figuras como essa, e ao irem moldando retomam e elaboram inconscientemente um elemento tão importante no culto a Exu.

Comun. \& Inf., Goiânia, GO, v. 19, n. 2, p. 53-70, jul./dez. 2016. 
Figura 6 - Assentamento de Exu

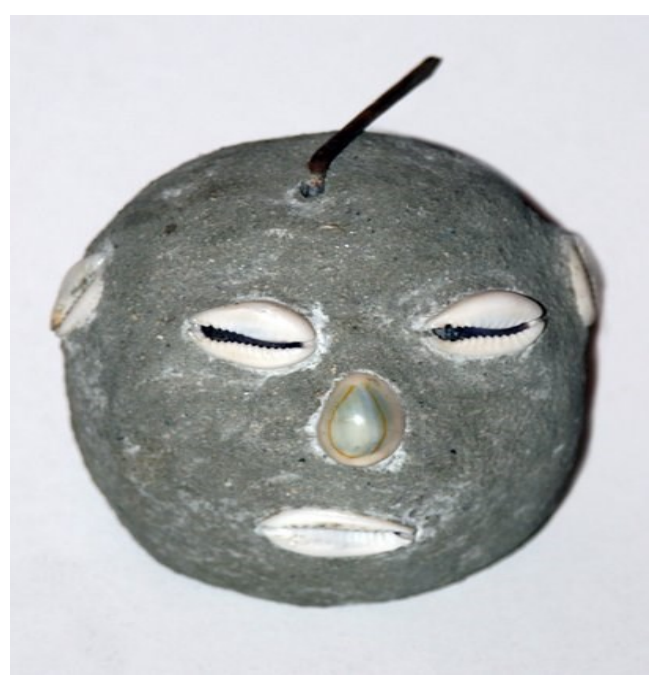

Fonte: http://pt.wikipedia.org/wiki/Ficheiro:Eleggua2005.jpg

O orixá mensageiro é Exu (ver figura 7), o que conduz o pedido dos homens aos outros deuses. Segundo Prandi (2005) Exu é principio de tudo, o movimento, e nada pode acontecer sem sua presença, nem mesmo em pensamento. Portanto, nada ocorre sem a interferência desse orixá, por isso ele é sempre o primeiro a ser homenageado nos cultos, sendo, assim, necessário permitir o movimento para que o evento se realize.

Ele é um orixá astucioso, vaidoso, inteligente, muito sábio, conhecedor dos saberes sobre a natureza humana e dos assuntos mundanos, por isso ao chegar ao Brasil, foi erroneamente sincretizado como o diabo cristão. Os missionários se apropriaram dessas características para o tornarem símbolo da maldade e do ódio. Conforme Verger (1980) e Prandi (2005), Exu não é completamente bom nem mau. Ele age de acordo com o tratamento e a solicitação que a ele fazem, pois na religiosidade africana não se reconhece essa oposição: a dualidade entre o bem e o mal.

Figura 7 - Exu

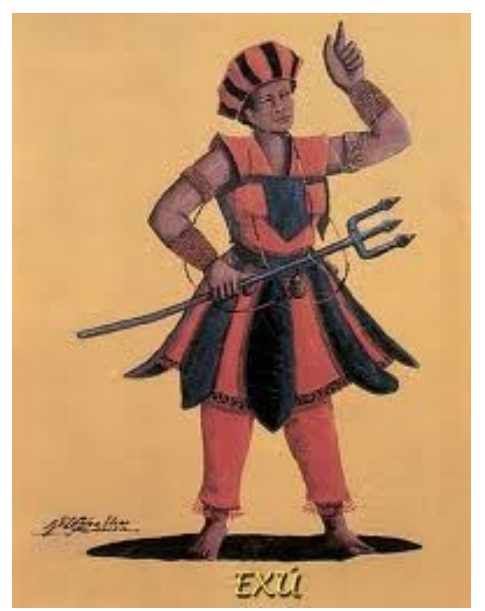

Fonte: http://www.feesperancaecaridade.org

Comun. \& Inf., Goiânia, GO, v. 19, n. 2, p. 53-70, jul./dez. 2016. 
Conjectura-se que para os moradores itamatatiuenses, essas informações sobre sua ancestralidade - de onde vieram e quais valores pertencem a sua linha genealógica - podem torná-los orgulhosos, e contribuir para preservação da memória e afirmação da identidade. Isso ocorre, pois segundo Pitta (2008), o mito fornece modelos de comportamento, ou seja, permite a construção individual e coletiva da identidade.

\section{CONSIDERAÇÕES FINAIS}

A junção de vozes dos moradores Itamatatiuenses permeada de simbolismos e claraboias, possibilitou relevar alguns segredos adormecidos por valores cristãos. Desvendálos é facultar às novas gerações, a chance de conhecer sua ancestralidade com heróis e guerreiros míticos africanos.

Enquanto na sociedade pós-moderna, o homem volta, como afirma Bordenave (1982), a revalorizar o colóquio, o bate-papo, a comunicação pessoa a pessoa, reencontrando o verdadeiro homem social, os moradores da Comunidade de Itamatatiua nunca deixaram a comunicação oral desaparecer. Ao contrário, é por meio da oralidade que as tradições permanecem na memória social dos moradores, o que hoje é objeto de estudo de pesquisas por uma sociedade já tão hibridizada.

As narrativas e trajetórias heroicas africanas podem auxiliar essas gerações, a tecer e a compor seus enredos, embalados pelo respeito às tradições e aos ancestrais, como os ensinamentos da Senhora Nanã, a irreverência de Exu para o aprendizado, a vontade de vencer as adversidades da guerreira Iansã, a inteligência e justiça de Xangô e o poder das artes de Oxalá.

Compreender essas narrativas míticas pode ajudar na ressignificação da vida de indivíduos, que são colocados à margem por forças políticas, educacionais e sociais desiguais e excludentes. Dessa forma, esta pesquisa considera os mitos da cultura africana como elementos de informação, preservação e memória na Comunidade Quilombola de Itamatatiua a partir da oralidade, da fala - elementos que demarcam um modelo informacional com estruturas materiais e simbólicas de um universo cultural de ser e estar dessa Comunidade.

Logo, analisar as narrativas míticas em linhas diacrônicas e sincrônicas é contribuir com o desvendamento de riquezas e tradições adormecidas em um passado de opressão e repressão, que pode ser reconstruído e devolvido às populações que desconhecem sua própria ancestralidade. Conclui-se que os estudos memorialísticos ajudam a rememorar as histórias de comunidades identitárias, a exemplo da Comunidade Itamatatiuense, onde a comunicação, a

Comun. \& Inf., Goiânia, GO, v. 19, n. 2, p. 53-70, jul./dez. 2016. 
informação e a religiosidade se constituem como uma tríade dialógica e processual cercada de rituais, simbolismo, ancestralidade e memória - elementos necessários à continuidade e sobrevivência desses remanescentes quilombolas.

\section{REFERÊNCIAS}

AQUINO, M. A.; PEREIRA, C. C. M. A presença das narrativas míticas de ancestralidade africana como elementos de informação e preservação da memória. Ponto de Acesso, Salvador, v. 6, n.2, p. 110-135, ago. 2010.

BORDENAVE, J. D. O que é comunicação. São Paulo: Brasiliense, 1982.

BRASIL. Ministério da Cultura. Instituto do Patrimônio, Histórico e Artístico Nacional. Inventário Nacional de bens móveis e integrados Maranhão e Piauí: Capela de Sta. Tereza D’Ávila, Itamatatiua, Alcântara. São Luís: MinC/ IPHAN, 1999. v. 12.

DURAND, G. As estruturas antropológicas do imaginário: introdução à arquetipologia geral. Tradução Hélder Godinho. São Paulo: WMF Martins Fontes, 1997.

DURAND, G. O imaginário: ensaio acerca das ciências e da filosofia da imagem. Tradução René Eve Levié. Rio de Janeiro: DIFEL, 1998.

ELIADE, M. Tratado de história das religiões. 3. ed. São Paulo: Martins Fontes, 2008.

GEERTZ, C. A interpretação das culturas. Rio de Janeiro: LTC Editora, 1989.

HARTMANN, F. O filósofo instruído por deus: uma introdução aos estudos de suas obras. Viena: Sociedade das Ciências Antigas, 1980.

LOZANO, J. E. A. Prática e estilos de pesquisa na história oral contemporânea. In: AMADO, J.; FERREIRA, M. de M. (Coords.). Usos \& Abusos da história oral. Rio de Janeiro: EFG Editora, 1996. cap. 2.

LOWENTHAL, D. The past is a foreign country. United Kingdom: Cambridge University Press, 1985.

MOLINA, S. R. A Morte da tradição: a Ordem do Carmo e os escravos de Santa contra o Império do Brasil (1850-1889). 2006. 309 f. Dissertação (Mestrado em História Social)- Faculdade de Filosofia, Letras e Ciências Humanas, Universidade São Paulo, São Paulo, 2006.

NASCIMENTO, A.Candomblé. Wikipédia. Disponível em:

$<$ http://pt.wikipedia.org/wiki/Candombl\%C3\%A9\#cite note-11>. Acesso em: 10 ago. 2010.

OXUM. In: DICIONÁRIO Wikipédia. Disponível em: $<$ http://pt.wikipedia.org/wiki/Oxum $>$. Acesso em: 20 ago. 2010.

PITTA, D. P. R. A dinâmica dos quatro elementos no candomblé. In: COLÓQUIO GASTON BACHELARD: CIÊNCIA E ARTE, 2, Anais... Salvador: [s. n.], 2008.

PRANDI, R. Conceitos de vida e morte no ritual da axexê: tradição e tendências recentes dos ritos funerários no candomblé. In: MARTINS, C.; LODY, R. (Orgs.). Faraimará, o caçador traz alegria: Mãe Stella, 60 anos de iniciação. Rio de Janeiro, Pallas, 1999.

Comun. \& Inf., Goiânia, GO, v. 19, n. 2, p. 53-70, jul./dez. 2016. 
PRANDI, R. Mitologia dos orixás. São Paulo: Companhia das Letras, 2000.

PRANDI, R. Segredos guardados: orixás na alma brasileira. São Paulo: Companhia das Letras, 2005.

CANSÃO Nova. Santa Teresa de Ávila (Santa Teresa de Jesus). Disponível em:<

http://santo.cancaonova.com/santo/santa-teresa-de-avila-santa-teresa-de-jesus/ > . Acesso em: 22. ago. 2010.

SANTOS, G.; REIS, M.; OOSTERBEEK, L. Quilombos e globalização: um estudo arqueológico sobre identidades e mecanismo de adaptação. [S. 1.]: Portugal Brasil Agora 2012.2013, 2010.

Disponível em:<http://projetoportoseguro-maranhao.blogspot.com/2010/02/quilombos-e-globalizacaoum-estudo_28.html>. Acesso em: 20 jul. 2010.

SILVA, V. G. da. Candomblé e umbanda: caminhos da devoção brasileira. 3. ed. São Paulo: Selo Negro, 2005.

TEIXEIRA, M. C. S. O Concreto e o simbólico no cotidiano escolar: as abordagens de Michel Mafesolli e José Carlos de Paula Carvalho. Educação e sociedade: [s. 1.], n. 38, p. 91-99, abr. 1991.

VALENTE, A. L. E. F. O Negro e a Igreja Católica. Campo Grande, MS: CECITEC/UFMS, 1994.

VANSINA, J. A tradição oral e sua metodologia. In: KI-ZERBO, J. (Org.). História geral da África: metodologia e pré-história na África. São Paulo: Ática; [Paris]: Unesco, 2010. cap. 7, v. 1.

VERGER, P. Iniciação. In: CARYBE. Iconografia dos deuses africanos no Candomblé da Bahia. Salvador: Raízes, 1980.

Recebido em: 21/07/2015

Aceito em: 16/11/2015

Publicado em: 31/12/2016

Comun. \& Inf., Goiânia, GO, v. 19, n. 2, p. 53-70, jul./dez. 2016. 